\title{
Cecal carcinoma: Initially diagnosed as Crohn's disease on small bowel follow-through
}

\author{
Donald H Taves MD FRCPC, Linda Probyn BSc PT
}

DH Taves, L Probyn. Cecal carcinoma: Initially diagnosed as Crohn's disease on small bowel follow-through. Can J Gastroenterol 2001;15(5):337-340. Lesions in the terminal ileum are often difficult to visualize on routine small bowel follow-through (SBFT) and may require further investigation to rule out associated abnormalities in the ileocecal valve or cecum. This may be done by peroral pneumocolon at the same sitting as the SBFT, but may require bowel preparation. Two cases of cecal carcinoma that were initially diagnosed as Crohn's disease on SBFT without further investigation of the cecum are reported.

Key Words: Cecal carcinoma; Peroral pneumocolon; Small bowel follow-through

\section{Carcinome cæcal initialement diagnostiqué comme maladie de Crohn lors d'un transit du grêle}

RÉSUMÉ : Les lésions de l'iléon terminal sont souvent difficiles à percevoir lors d'un transit du grêle de routine et des études plus approfondies sont parfois nécessaires pour écarter certaines anomalies associées de la valvule iléo-cæcale ou du cæcum. Cela peut être fait par pneumocolie perorale lors de la même séance de transit, mais peut aussi requérir une préparation intestinale. Sont ici présentés deux cas de carcinome cæcal d'abord diagnostiqués comme maladies de Crohn lors d'un transit du grêle sans autre étude du cæcum.
$\mathrm{S}_{\mathrm{in}}^{\mathrm{m}}$ mall bowel follow-through (SBFT) continues to play an mportant role in the diagnosis of lesions occurring in the ileum (1). One of the most important indications for small bowel barium studies is for suspected Crohn's disease (1). Investigations have shown good accuracy of a well performed SBFT in the diagnosis of Crohn's disease in the majority of cases $(2,3)$. However, lesions in the terminal ileum can sometimes be difficult to visualize and interpret, and, therefore, require further investigations to clarify the diagnosis. Associated abnormalities may also occur more distally in the ileocecal valve, cecum or ascending colon. If these regions are not visualized well initially on SBFT, further investigations may be required to assist in the interpretation and clarification of findings.

Two separate cases of adenocarcinoma of the cecum that were both initially diagnosed as Crohn's disease by SBFT are reported. Both of these cases stress the importance of evaluating the cecum when the terminal ileum, ileocecal valve or cecum appears to be abnormal, or if patients have symptoms that warrant further investigation. The present report discusses whether a barium peroral pneumocolon should be performed for reassurance of the diagnosis when the terminal ileum, ileocecal valve or cecum is not adequately visualized. This procedure can be done in the same sitting as an SBFT and helps to determine a more definitive diagnosis.

To obtain a satisfactory SBFT study, it is important to have reasonable flow of contrast through the bowel. Fecal material in the bowel can slow transit time and obscure the findings. Traditionally, no routine bowel preparation has been given to patients requiring an SBFT. However, bowel preparation may be a reasonable and necessary step in order

Department of Diagnostic Radiology, The University of Western Ontario, London, Ontario

Correspondence and reprints: Dr Donald H Taves, The University of Western Ontario, Department of Diagnostic Radiology,

St Joseph's Health Care London, 268 Grosvenor Street, London, Ontario N6A 4V2. Telephone 519-646-6100 ext 64644,

fax 519-646-6204, e-mail vickie.kline@sjhc.london.on.ca

Received for publication November 1, 1999. Accepted December 2, 1999 


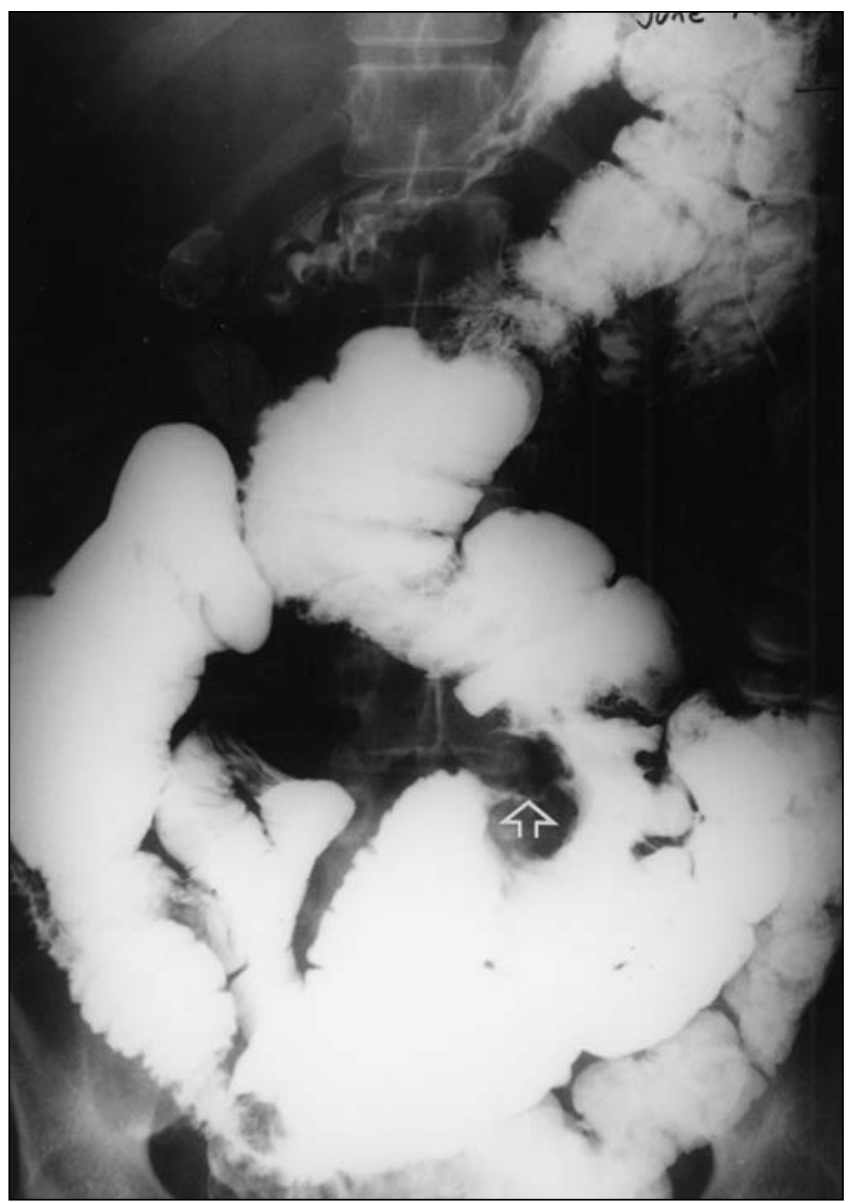

Figure 1) Small bowel follow-through demonstrating malpositioned cecum and narrowed terminal ileum (arrow)

to gain more diagnostic information and to decrease stool burden, particularly if a peroral pneumocolon is performed in the same sitting.

\section{CASE PRESENTATIONS}

Case 1: A 52-year-old woman had a significant gastrointestinal history including episodes of gallstone pancreatitis (which resulted in a cholecystectomy), choledocholithiasis, pancreatic pseudocyst and post-endoscopic retrograde choledochopancreatography pancreatitis. She also had a stool culture that was positive for Plesiomonas shigelloides. In March 1989, a double contrast upper gastrointestinal series and dedicated small bowel examination were performed that showed thickening of mucosal folds in the terminal ileum associated with a large ileocecal valve. The cecum was malpositioned and located in the midabdomen. There was a 'picket fence' appearance to the distal $12 \mathrm{~cm}$ of the terminal ileum (Figures 1,2). Considerations for the diagnosis included an atypical appearance of Crohn's disease, lymphoma, inflammation secondary to pancreatic fluid or hemorrhage within the bowel wall.

A repeat dedicated small bowel examination was performed three months later. A narrow $3 \mathrm{~cm}$ long stricture was present in the most distal ileum associated with mini-

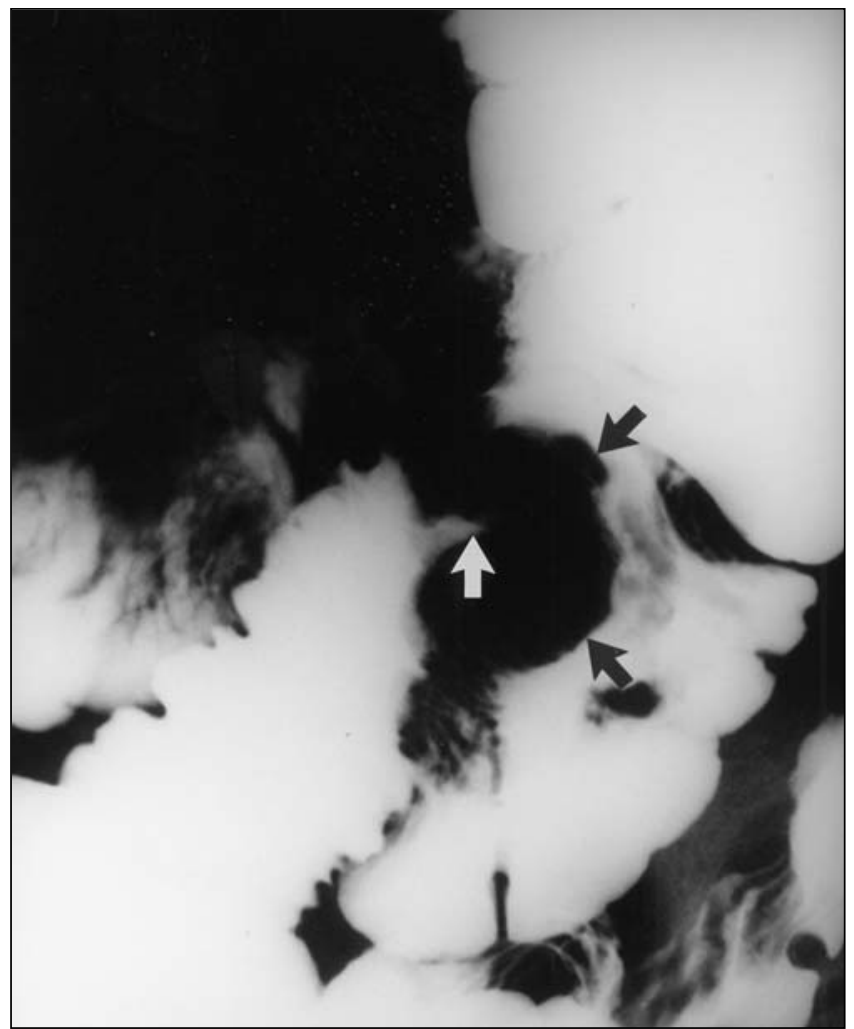

Figure 2) Detailed view of small bowel follow-through demonstrating narrowed terminal ileum (white arrow) and a large lobulated ileocecal valve (black arrows)

mal dilation of the adjacent $25 \mathrm{~cm}$ of small bowel. Minimal nodularity of mucosa was identified in a short segment of ileum adjacent to the stricture. The cecum was again malpositioned. The differential diagnosis of the stricture included Crohn's disease or a postinfectious stricture. No further investigations were performed at that time.

Shortly after the second SBFT, the patient presented to hospital with a bowel obstruction that was thought to be secondary to inflammation from presumed Crohn's disease. A hemicolectomy was performed and revealed adenocarcinoma of the cecum (Duke's C) involving the ileocecal junction and one sampled lymph node positive for malignancy.

Case 2: A 37-year-old woman presented with a history of right upper quadrant crampy abdominal pain in July 1997. An SBFT demonstrated that the proximal ascending colon was irregularly narrowed with a nodular mucosal pattern and areas of ulceration accompanied by foreshortening of the ascending colon. There was a short segment of terminal ileal disease involving the distal $2 \mathrm{~cm}$ of terminal ileum (Figure 3). The findings were consistent with Crohn's disease of the ascending colon and a short segment of the terminal ileum proximal to the ileocecal valve. No further investigations were done at that time, and the patient was treated with 5-acetylsalicylic acid and steroids for suspected Crohn's disease.

This patient subsequently became pregnant and soon after delivering the baby developed a mass in her right mid- 


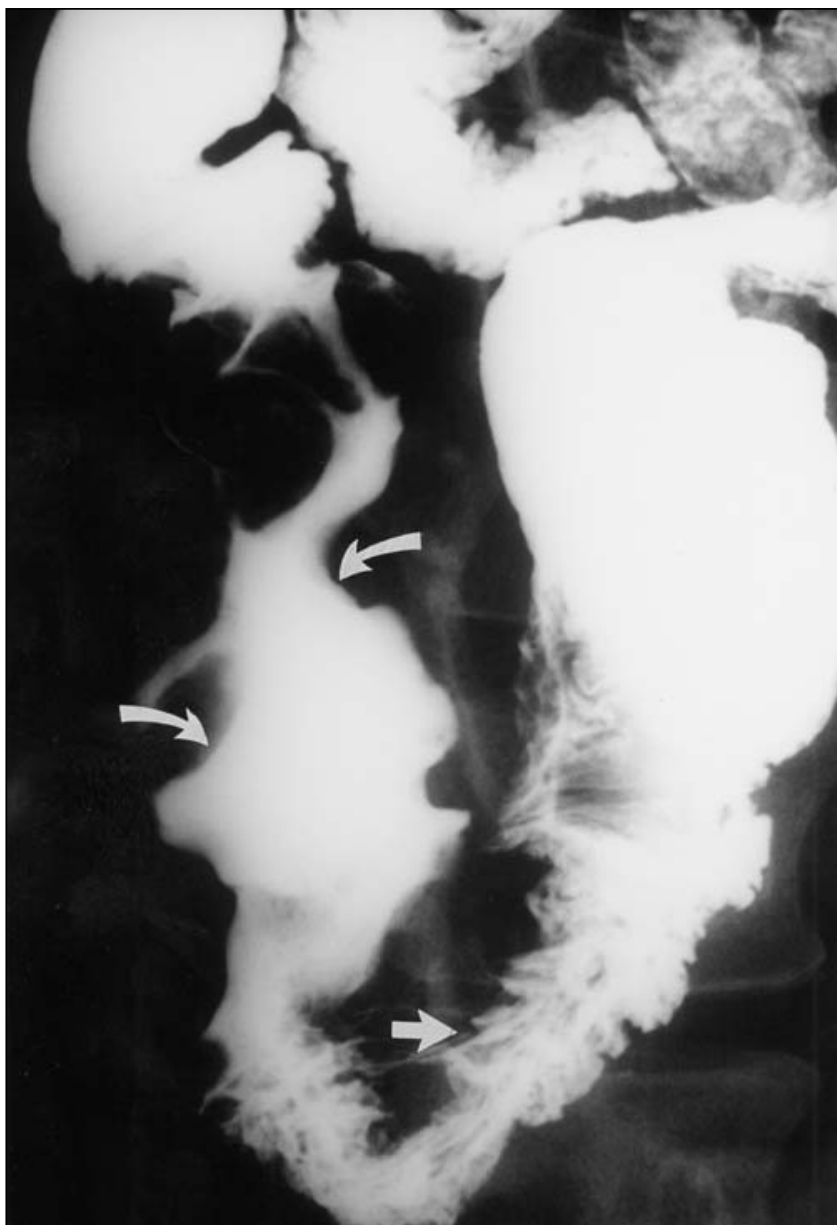

Figure 3) Small bowel follow-through demonstrating narrowed and grossly nodular cecum and ascending colon with distorted folds in the terminal ileum

abdomen with increased abdominal pain and nausea. An abdominal ultrasound in April 1998 noted marked circumferential thickening of the wall of the cecum and ascending colon corresponding to the changes consistent with Crohn's disease in the previous SBFT. There was a small collection of fluid contiguous with the ascending colon, thought to represent a small abscess. A repeat SBFT in May 1998 showed a mass involving the cecum and ascending colon, the appearance of which was suggestive of an adenocarcinoma (Figure 4). This was confirmed by colonoscopy, and a right hemicolectomy was performed. The final diagnosis was an adenocarcinoma of the cecum and ileocecal junction (Duke's C) with two of the sampled lymph nodes positive for malignancy.

\section{DISCUSSION}

Peroral pneumocolon: Fluoroscopic spot films of the terminal ileum obtained at the conclusion of an SBFT may not adequately show the ileum, ileocecal valve and cecal tip (4). Peroral pneumocolon is a simple adjunct to the conventional SBFT, and involves retrograde insufflation of air per rectum to distend the ileum and cecum after barium (taken orally) has reached the ascending colon during the

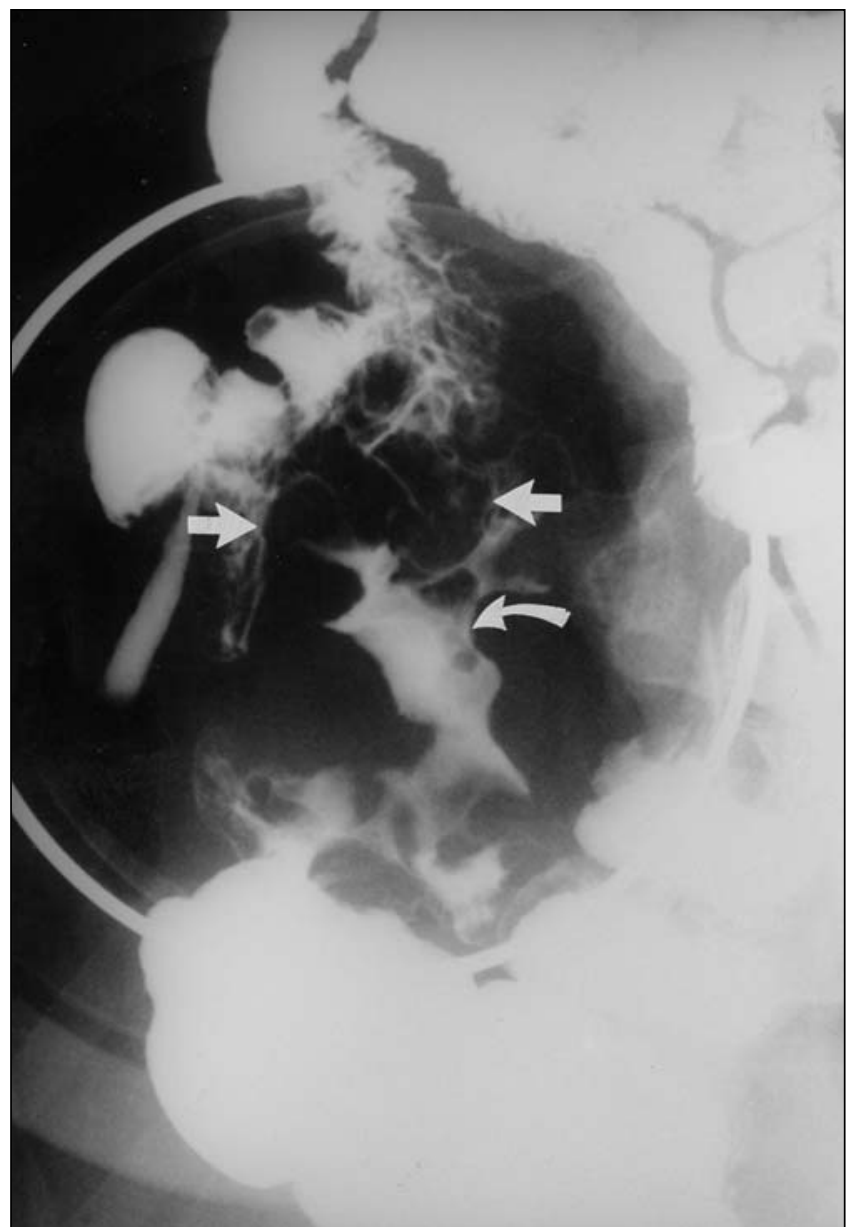

Figure 4) Small bowel follow-through demonstrating large nodular mass involving cecum and terminal ileum

SBFT (4). Insufflation of air with the patient in the prone position allows reflux into the distal ileum (5). The examination is indicated if the patient is unable to tolerate barium enema studies, if a detailed view of the ileocecal region is necessary (especially if inflammatory bowel disease is suspected), for re-evaluation of a suspicious region noted on an SBFT or if filling defects are noted within the right colon (5).

Studies have confirmed the diagnostic value of the test, such that in most cases retrograde air insufflation yielded additional diagnostic information (4). As well, the test is feasible for all age groups (4). It does not require extra preparation and is an easy, reliable and effective adjunct to the SBFT (4). The retrograde examination of the distal small bowel has been described as being frequently superior to the conventional SBFT (6). It takes about 6 to $8 \mathrm{~min}$ to perform, so it is not a time-consuming additional examination (7).

Air insufflation can cause patient discomfort, which must be considered when using this technique (4). Although patient discomfort has been described, there were no reported procedure-related complications (4). Some authors recommend the use of glucagon to reduce discomfort and promote opening of the ileocecal valve; however, this is not 
routinely given to patients $(5,7)$. Despite the benefits described, the peroral pneumocolon is not an alternative to the SBFT, but should be used as an adjunct, especially when further clarification of the diagnosis is needed (4).

Bowel preparation: Accurate radiology of the colon is the result of thorough cleansing of the wall and lumen before examination (8). Bowel preparation is important because of the danger of mistaking a tumour for the ileocecal valve or fecal material (9). In addition to simulating polyps, retained fecal material slows the flow of barium and prevents uniform coating of the mucosal surface (10). Recommendations for bowel preparation before a barium enema are clearly documented and include an oral polyethylene glycol preparation the night before the examination, or a high cleansing enema the morning of the examination $(9,11)$. Most centres do not routinely request bowel preparation before SBFT, but the patients are asked to have nothing to eat or drink following midnight the night before the test. Some technicians report that occasionally fecal material may remain in the cecum or ascending colon, which can retard the flow of contrast material, delaying the procedure. If a peroral pneumocolon is then performed, fecal material may obscure the findings, causing inaccuracies. It has been reported that missed lesions are often due to poor bowel preparation, which stresses the importance of a clean colon, especially if imaging the cecum (12). Therefore, bowel preparation may be necessary before a small bowel study, particularly if there is a possibility of peroral pneumocolon. Cecal carcinomas: Cecal carcinomas can be large, proliferative polypoidal masses that may extend to involve the proximal small bowel, mesentery or distal ascending colon. These have been described as closely resembling other pathologies such as Crohn's disease (11). It has been reported that pseudopolyps of inflammatory bowel disease can occur in large clusters or masses that may be indistinguishable from carcinoma (13).

\section{REFERENCES}

1. Maglinte DDT, Kelvin FM, O'Connor K, Lappas JC, Chernish SM. Current status of small bowel radiography. Abdom Imaging 1996;21:247-57.

2. Carlson HJC. Perspective: The small-bowel examination in the diagnosis of Crohn's disease. AJR Am J Roentgenol 1986;147:63-5.

3. Ott DJ, Chen YM, Gelfand DW, et al. Detailed per-oral small bowel examination vs enteroclysis. Part II: Radiographic accuracy. Radiology 1985;155:31-4.

4. Wolf KJ, Goldberg HI, Wall SD, Rieth T, Walter EA. Feasibility of the peroral pneumocolon in evaluating the ileocecal region. AJR Am J Roentgenol 1985;145:1019-24

5. Kressel HY, Evers KA, Glick SN, Laufer IJ, Herlinger H. The peroral pneumocolon examination: Technique and indications. Radiology $1982 ; 144: 414-6$

6. Goldberg HI, Jeffrey RB. Recent advances in the radiographic evaluation of inflammatory bowel disease. Symposium on inflammatory bowel disease. Med Clin North Am 1980;64:1059-81.

7. Kelvin FM, Gedgaudas RK, Thompson WM, Rice RP. The peroral
There are reports that describe carcinomas of the cecal region that have been misdiagnosed by barium enema studies (1). Before the use of air contrast, $20 \%$ of colon cancers were overlooked with examination by barium enema (14). However, there are few reports in the literature of cecal carcinomas that have been misdiagnosed by SBFT. This is likely due to the fact that the contrast investigation of choice for the suspected diagnosis of cecal carcinoma is a barium enema. However, patients who are investigated for suspected Crohn's disease are likely to undergo an SBFT initially, in order to search for terminal ileal disease.

\section{CONCLUSIONS}

In both cases presented, an abnormal or prominent ileocecal valve or terminal ileum was noted on SBFT with a presumptive diagnosis of Crohn's disease, but the area was not further examined with air contrast. Short et al (9) recommended routine examination of terminal ileitis. This early recommendation emphasizes the need to examine abnormalities of the terminal ileum adequately. Peroral pneumocolon is a well tolerated and effective diagnostic tool to be used when abnormalities of this area appear on the SBFT. The examination can be done in the same sitting as the SBFT and does not require further preparation at the time of the study. It is time efficient, and does not cause unnecessary anxiety by scheduling a second examination to clarify a questionable diagnosis.

It is also important to stress the need to prepare the bowel adequately for examinations, in order to reduce study delay and increase study accuracy. This is particularly important in cases that may require a peroral pneumocolon at the same sitting. Judicious use of air contrast with SBFT and use of bowel preparation help to increase overall diagnostic accuracy for lesions involving the distal ileum, ileocecal junction and cecum.

pneumocolon: Its role in evaluating the terminal ileum. AJR Am J Roentgenol 1982;139:115-21.

8. Kemp Harper RA. The radiological spectrum of Crohn's disease. Proc R Soc Med 1971;64:1181-6.

9. Short WF, Smith BD, Hoy RJ. Roentgenologic evaluation of the prominent or the unusual ileocecal valve. Med Radiogr Photogr 1976;52:2-26

10. Laufer I. Air contrast studies of the colon in inflammatory bowel disease. CRC Crit Rev Diagno Imaging 1977;9:421-47.

11. Simpkins KC. Double-contrast: colon. Clin Gastroenterol 1984;13:99-121.

12. Kelvin FM, Gardiner R, Vas W, Stevenson GW. Colorectal carcinoma missed on double contrast barium enema study: A problem in perception. AJR Am J Roentgenol 1981;137:307-13.

13. Fishman RS, Fleming CR, Stephens DH. Roentgenographic simulation of colonic cancer by benign masses in Crohn's colitis. Mayo Clin Proc 1978;53:447-9.

14. Clarke AM. Diagnostic errors in carcinoma of the colon. NZ Med J 1969;69:38 


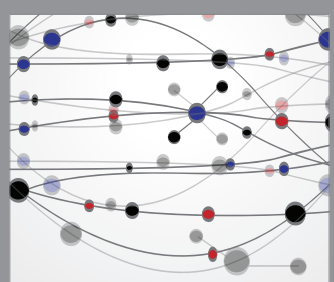

The Scientific World Journal
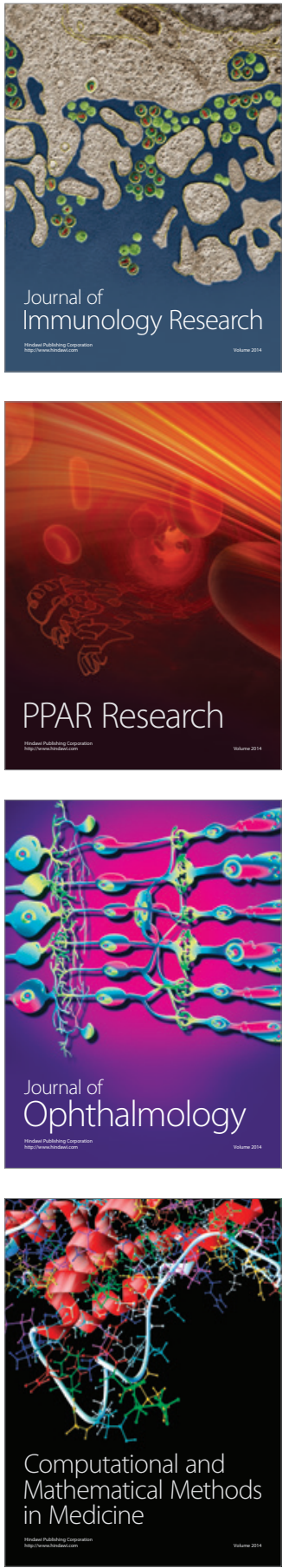

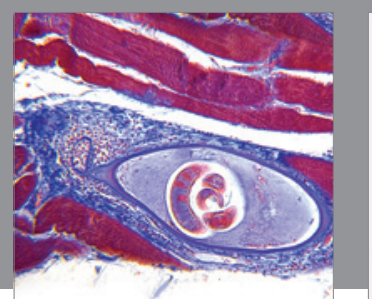

Gastroenterology Research and Practice

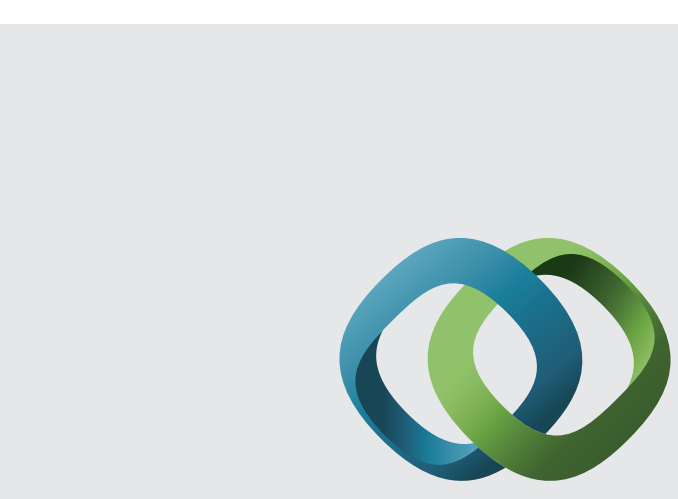

\section{Hindawi}

Submit your manuscripts at

http://www.hindawi.com
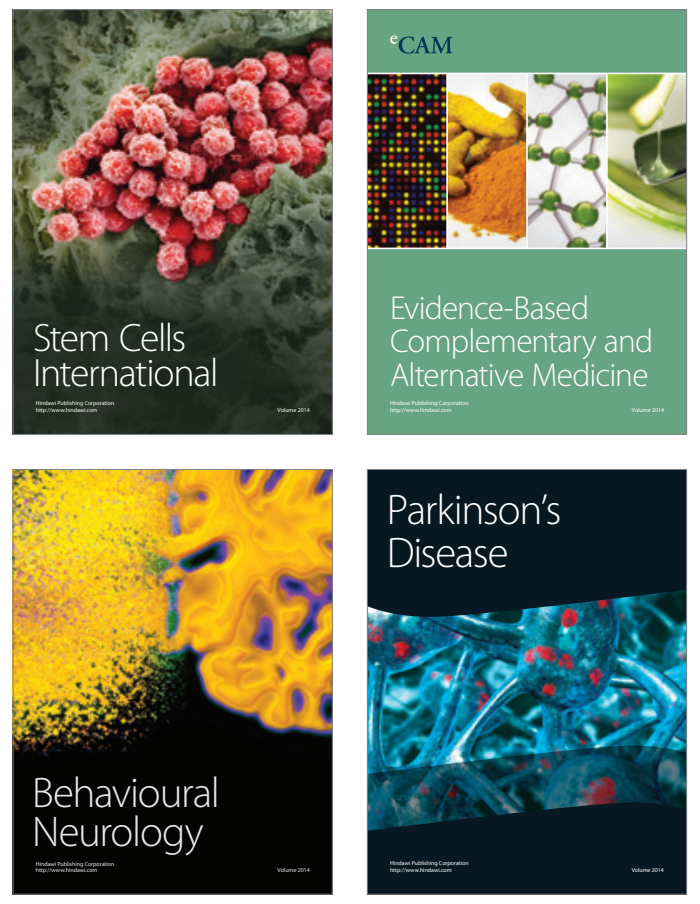
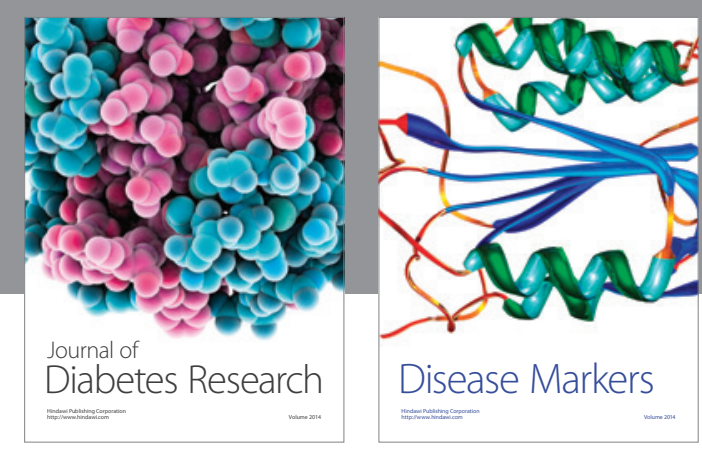

Disease Markers
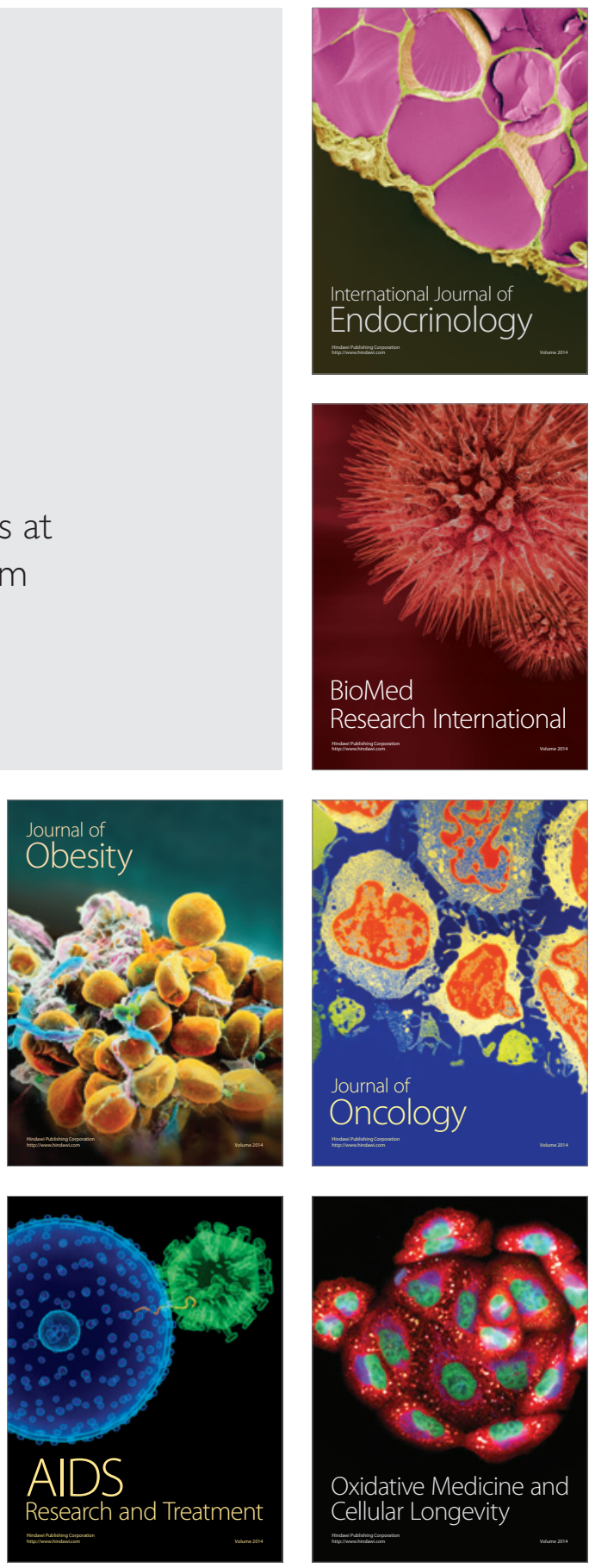